\title{
Commentary on promoting positive communication environments: a service evaluation: The communication partnership as a focus for change
}

Purpose: This article debates the complexities of intervening with adults with learning disabilities and support staff in the natural environment and the challenges of evaluating change.

Approach: A critical review of the relevance and amenability of communication partnerships for interventions that promote communication growth in context was carried out. Particular consideration was given to the mechanism for change and implications for research design.

Findings: The communication partnership is a reasonable focus for interventions aiming to promote the communication of adults with learning disabilities. Combining instructional training with in situ coaching appears to provide the most effective approach. Bringing about change within the dynamic context of communication is challenging and may benefit from an open, investigative design.

Originality: This paper synthesises the available evidence on intervening in the communication environment and debates the potential of realist evaluation as a context-focused research design. 
Harding et al reported an evaluation of a service-based, intervention that enskilled support staff to facilitate communication with adults with learning disabilities. A dynamic process, communication occurs within the social space occupied by people, such as residential, day and educational settings, where information is shared, relationships develop, and interactions proliferate for multiple purposes. Thus the natural environment where communication actually happens, referred to as the communication environment, would seem to be an appropriate place to bring about change to the experiences of adults with learning disabilities and the social opportunities available to them. Back in the nineties, Ware $(1996, p .1)$ summarised the good communication environment as one where '...people get responses to their actions, get the opportunity to give responses to the actions of others, and have the opportunity to take the lead in interaction'. Thus, the communication relationships experienced by individuals and the people who support them, referred to as communication partners, are of interest.

\section{Bi-directional influences}

The communication process is subject to bi-directional influences. Any difficulties that arise in communication do not derive solely from people with learning disabilities, but rather are viewed as outcomes of the interactional process (Nind et al., 2001). The competencies that each person brings to a partnership are mutually influential: the contributions of one affects the other, and vice versa. Around twenty years ago, Kagan (1998, p.817) captured the communication partnership as an 'equation' made up of the skills and experiences of the participants and the availability and use of resources. Where differences exist between the interactants, the equation is susceptible to imbalance, with the locus of control likely to be centred 
on the more able person (Bunning, 2011). Depending on the skill set of the person with particular communication needs, the communication partner is required to shape and adapt their usual way of communicating to achieve a more balanced interactional relationship. Simmons-Mackie and Kagan (1999) observed that it is possible to promote, or alternatively cast in doubt, the communication skills of the individual through partner skills usage. Two main types of communication error may occur in the communication partnership (Bunning, 2011). The first error type is when the partner fails to recognise and respond to the language and communication skills of the person. Referred to as a 'cycle of devaluation', the individual has few, meaningful opportunities to participate, which effectively hides their true competence. Joshua was a young man with intellectual disabilities and cerebral palsy who was dependent on a wheelchair for his mobility needs. He attended a day service where he was supported to take part in a range of activities. He communicated through facial expression, vocalisations, hand gestures directed to things in his immediate environment and jerking movements of his torso. Joshua was able to communicate his agreement or disagreement to various propositions but relied heavily on his support worker to interpret his meanings. Formal assessment of his communication skills revealed a large receptive vocabulary and understanding for complex concepts and structures. However, the communication environment was geared towards the more limited communication skills of the majority and provided him with few opportunities to use his natural competence. The second error type, referred to as a 'cycle of inflation', assumes a higher level of communicative competence in the person than is really the case. Eloise had understanding for single concrete ideas and experienced difficulties maintaining her attention. The support staff made no adjustment to utterance complexity and communication rate 
when communicating with her. Eloise typically sat on the margins of the conversation, unable to access turns and to use her available skills.

Earlier research found that direct support staff were not always prepared sufficiently to provide skilful communication support for the wide range of individual needs they encountered in their work (see Bradshaw, 2001; McConkey et al., 1999). Not restricted to individuals with more complex needs, disparities in the communication process between staff and individuals with borderline-mild learning disabilities have been reported, affecting synchrony of verbal and non-verbal aspects (Reuzel et al., 2013a), and pattern of turn occupation by staff where direct questions dominated and there was neglect of some spontaneous contributions by service users (Reuzel et al., 2013b). Dalton and Sweeney (2013) reported that whilst support staff acknowledged the importance of good communicative support to the improved quality of life amongst people with learning disabilities, they also recognised their own lack of knowledge and poor availability of specific resources as problematic. However, a lack of congruence between staff identification of preferred communication strategies and their observed usage suggested that increasing knowledge was not sufficient to alter practice (Healy and Noonan Walsh, 2007). Furthermore, interventions involving classroom-based learning did not transfer automatically into everyday use (Chadwick and Joliffe, 2008; McLeod et al., 1995). Other approaches have attempted to circumvent the problem of transfer through situated learning: problem-solving in life-simulated scenarios (e.g. MacMillan et al., 2000); classroom-based instruction with partnership practice or an immersion approach where the natural environment is targeted and staff act as agents for change (e.g. Meuris et al., 2015); video playback, guided observation and verbal 
feedback (e.g. McConkey et al., 1999, Money, 1997; Purcell et al., 2000); training in the form of prompts given to support staff via one-way radio in situ (Zoder-Martell et al. 2014). In a comparison of three models of speech \& language therapy service delivery, combining staff training and direct work with service user and staff member was found to be more effective than either approach in isolation (Money, 1997). More recently, a systematic review of training initiatives delivered to support staff concluded that programmes incorporating opportunities for trying out communication strategies and for receiving feedback on progress were associated with positive outcomes for service users (van der Meer et al., 2017). Thus, it would seem logical that any attempt to improve the social experiences of people with particular communication needs necessitates intervening at the level of the communication partnership in practice.

\section{One size fits all?}

Given the diversity of communication skills amongst adults with learning disabilities, a 'one size fits all' approach to promoting skillful communication support amongst staff is probably not useful. Training in particular Alternative and Augmentative Communication (AAC) methods, such as manual signing, may be more straightforward because of the universal code, i.e. sign, that is being introduced to the communication environment. Even then, individual learning and the nature of accessible communication opportunities will vary from person to person. An earlier study by Purcell et al. (2000) involved a work-based training programme that was specifically designed around the assessed needs of people with learning disabilities and their support staff. It involved video recordings taken before and after the intervention. Reported gains in staff responsiveness correlated significantly with an 
increase in client communication acts. The mechanisms underlying the changes centred around the work-based, client-centred, 'mentor-guided' approach that was implemented. A number of factors are critical here: comprehensive assessment of individual communication needs used to inform the content of the skills development programme, an intervention situated in the natural environment where communication takes place, and a mentoring approach designed to encourage staff, provide feedback and support a change process. Using a nuanced approach that combined direct instruction with an immersion approach, Meuris et al. (2015) demonstrated not only increased manual sign production by both staff and adults with intellectual disabilities, but also growth in communicative functions used in narratives. Whilst the changes occurred 12 months after the start of the intervention, questions of maintenance and recapitulation of learning remained. The latter point is particularly relevant to what constitutes a trigger for re-referral: the support needs of a service user or the skill needs of a staff member?

Potentially more challenging is the type of support suited to people with severeprofound and multiple intellectual disabilities, where communication relies on subtle body behaviours, such as fleeting eye gaze, minor body movements and vocalisations (Grove et al., 1999). The communication partner is required to observe the individual closely, to detect changes in behaviour, to recognise gestures that are often idiosyncratic, and to make the best interpretation of meaning as possible. In so doing, the communication partner draws on knowledge and daily experiences of the individual, observes contextual factors apparently connected to the individual's behaviour, tries out a response and checks the person's reaction as a guide to the relevance of the interpretation. In terms of staff training, this is a complex 
proposition, because it requires training in close observation of and support for the individual's repertoire of communication behaviours. Two different interventions provide examples of this type of approach. Intensive Interaction (Nind and Hewitt, 2001) coaches partners to observe and tune-in to the individuals they support, developing playful interactional sequences in the here and now. Advancing communication towards something more purposeful is afforded by narrative-based approaches that reference events outside of the moment. Storysharing®, focused on the development of personal narratives combines instructional training and immersive activities that train staff to: recognise the real-life experiences of the people they support; develop the narrative in partnership practice using communicative scaffolding; to work as a partnership in retelling the story to others (Grove and Harwood, 2013). Reported outcomes include a more complete narrative and a discourse structure that demonstrates a greater balance of contributions (see Bunning et al., 2017).

\section{Realist evaluation}

Having established the relevance of intervening in the communication partnership, there is the issue of evaluation. Observation methodologies offer useful ways to capture critical features of partnership interactions, provided that the phenomena of interest are defined clearly and any coding frameworks have proven reliability. Structured approaches have been used to quantify the range and frequency of communication characteristics: communicative modalities employed by partners (e.g.

Bailey and Bunning, 2011); discourse initiations and responses, and pragmatics (e.g. Bunning et al., 2016). A more inductive approach is provided by conversational analysis to investigate talk-in-interaction, typically focusing on communication 
breakdown and repair (e.g. Finlay and Antaki, 2012). Such methods are labour intensive and require trained observers with time to carry out transcriptions that adhere to the appropriate conventions and analysis framework. Regardless of the method of choice, however, attention needs to be given to the attribution of change: how do we explain changes from baseline measures? Diversity of communication needs associated with learning disabilities and the range of staff skill sets challenge the evaluation process. Some contextual factors may trigger particular mechanisms that contribute to positive outcomes, whilst others may inhibit. For example, the dynamic of the staff team, the available skill mix of individuals, their experience and education, may variously affect staff responses to the training.

Realist evaluation, drawn from Pawson and Tilley's seminal work (1997), recognises that the interaction between context and mechanism is constant, and any impacts or outcomes stem from that interaction. It also recognises that what appears to work in one context, may not be replicated in another because of differences in the mechanisms for the change. Such an approach assumes that delivery of any intervention is testing a theory about the change process. This is done by testing clearly articulated hypotheses asking how the intervention works and for whom. In addition to collecting data for computing change pre- to post-intervention and carrying out a process evaluation (e.g. staff attendance of training events, compliance with programme requirements), data on specific aspects of the context that might influence outcomes and the particular mechanisms that might be creating change are also collected. Thus the realist evaluation encourages address of the question: why has the intervention worked in this setting as opposed that one? In this 
way, a more complete understanding of ecologically-focused interventions, particularly ones that are concerned with human communication, may be supported.

\section{Conclusions}

Given the diversity of communication skills and needs in the population with learning disabilities, what is the key to establishing communication growth in the environments where they live, work and socialise? Firstly, we need to place equal value on the different ways people communicate in any given setting. We need to recognise that whilst speech, which is usually at the top of the human communication hierarchy (Flewitt, 2006), is the most immediate form of communication for most people, for some individuals it is other forms, such as objects, body gestures, sign and graphic symbols. Secondly, beyond the form of the communication is the process whereby meanings are co-constructed within the communication partnership. With reference to the communication equation (Kagan, 1998; Simons-Mackie and Kagan, 1999), any assessment of the individual's communicative skills needs to include a detailed analysis of partnership interactions, which means drawing on the frameworks of applied linguistics (see Bunning et al., 2017). The resulting profile will not only inform a more nuanced approach to the immersive training but provide a baseline from which to compute changes. Thirdly, increasing the knowledge of support staff is not sufficient on its own. The most effective approaches appear to combine instruction with in situ practice.

Opportunities are provided to try out new strategies and techniques, to receive feedback and to feedforward. Fourthly, the challenge of evidencing and explaining change highlights the need for data collection beyond the observed skills of the communication partners (after Pawson and Tilley, 1997). This mean capturing 
contextual data, in this case the communication environment composed of the support staff - their skill sets, experience and personal attributes; the physical setting in terms of space and resources; the setting culture made up of organisational values, staff practices and managerial direction. Finally, it needs to be borne in mind that a re-referral to activate another cycle of the intervention is not only concerned with the changing needs of the adult with learning disabilities; but may be triggered by any aspect of the communication environment, including changes to the staff team, the adults with learning disabilities, the service organisation and management.

\section{References}

Bailey, P. and Bunning, K. (2011), "Narrative construction by an aided speaker: a pilot study", Journal of Assistive Technologies, Vol 5 No. 4, pp. 1754-9450.

Bradshaw, J. (2001), "Complexity of staff communication and reported level of understanding skills in adults with intellectual disability", Journal of Intellectual Disability Research Vol 45 No. 3, pp. 233-243.

Bunning, K., Gooch, L. and Johnson, M. (2016), "Developing the personal narratives of children with complex communication needs associated with intellectual disabilities: what is the potential of Storysharing ${ }^{\circledR}$ ?", Journal of Applied Research in Intellectual Disabilities Vol 30 No. 4, pp. 743-756.

Bunning, K. (2011), "Let me speak - facilitating communication", in Atherton, H.L. and Crickmore, D.J. (Eds.), Learning Disabilities: Towards Inclusion, $6^{\text {th }}$ Edition, Elsevier Ltd, London, pp. 91-12. 
Dalton, C. and Sweeney, J. (2013), "Communication supports in residential services for people with an intellectual disability", British Journal of Learning Disabilities, Vol 41 No. 1, pp. 22-30.

Finlay, F.M.L. and Antaki, C. (2012), "How staff pursue questions to adults with intellectual disabilities", Journal of Intellectual Disability Research, Vol 56 No. 4, pp. 361-370.

Flewitt, R. (2006), "Using video to investigate preschool classroom interaction: education research assumptions and methodological practices", Visual Communication, Vol 5 No. 1, pp. 25-50.

Grove, N. and Harwood, J. (2013), "Storysharing: Personal narratives for identity and community", in Grove, N. (Ed.), Using Storytelling to Support Children and Adults with Special Needs, Taylor \& Francis, London, pp. 102-110.

Healey, D. \& Noonan Walsh, P. (2007), "Communication among nurses and adults with severe and profound intellectual disabilities: predicted and observed strategies", Journal of Intellectual Disabilities, Vol 11 No. 2, pp. 127-141.

Kagan, A. (1998), "Supported conversation for adults with aphasia: methods and resources for training conversation partners", Aphasiology, Vol 12 No. 9, pp. 816830.

McConkey, R., Morris, I. and Purcell, M. (1999), “Communications between staff and adults with intellectual disabilities in naturally occurring settings", Journal of Intellectual Disability Research, Vol 43 No. 3, pp. 194-205.

McLeod, H., Houston, M. and Seyfort, B. (1995), “Communicative interactive skills training for caregivers of nonspeaking adults with severe disabilities", International Journal of Practical Approaches to Disability, Vol 9, pp. 5-11. 
Meuris, K., Maes, B. and Zink, I. (2015), "Teaching adults with intellectual disability manual signs through their support staff: a key word signing program", American Journal of Speech-Language Pathology, Vol 24 No. 3, pp. 545-560.

Nind, M., Kellett, M. and Hopkins, V. (2001), “Teachers' talk styles: communication with learners of with severe and complex learning difficulties", Child Language Teaching \& Therapy, Vol 17 No. 2, pp. 143-159.

Pawson, R. and Tilley, N. (1997). Realistic Evaluation, Sage, London.

Purcell, M., McConkey, R. and Morris, I. (2000), "Staff communication with people with intellectual disabilities: the impact of a work-based training programme", International Journal of Language \& Communication Disorders, Vol. 35 No. 1, pp. 147-158.

Reuzel, E., Embregts, P.J.C.M., Bosma, A. M.T, van Nieuwenhuijzen, M and Jahoda, A. (2013a), "Conversational synchronization in naturally occurring settings: a recurrence-based analysis of gaze directions and speech rhythms of staff and clients with intellectual disability", Journal of Nonverbal Behavior, Vol 37 No. 4, pp. 281-305.

Reuzel, E., Embregts, P.J.C.M., Bosma, A. M.T, van Nieuwenhuijzen, M and Jahoda, A. (2013b), "Interactional patterns between staff and clients with borderline to mild intellectual disabilities", Journal of Intellectual Disability Research, Vol 57 No.1, pp. 53-66.

Simons-Mackie, N. and Kagan, A. (1999), "Communication strategies used by 'good' versus 'poor' speaking partners of individuals with aphasia”, Aphasiology, Vol 13 Nos. 9-11, pp. 807-820.

van der Meer, L., Matthews, T., Ogilvie, E., Berry, A., Waddington, H., Balandin, S., O’Reilly, M., Lancioni, G. \& Sigafoos, J. (2017), "Training direct-care staff to provide 
communication intervention to adults with intellectual disability: a systematic review", American Journal of Speech-Language Pathology, Vol 26 No. 4, pp. 1279-1295.

Ware, J. (2003), Creating a Responsive Environment: For People with Profound \& Multiple Learning Difficulties, Fulton Publishers, London.

Zoder-Martell, K.A., Dufrene, B.A., Tingstrom, D.H., Olmi, D.J., Jordan, S.S., Biskie, E.M. and Sherman, J.C. (2014), "Training direct care staff to increase positive interactions with individuals with developmental disabilities", Research in Developmental Disabilities, Vol 35 No. 9, pp. 2180-2189. 